\title{
Preauricular Vertical Creases
}

Taro Shimizu and Yukinori Harada

Key words: bedside teaching, physical diagnosis

(Intern Med 58: 3067, 2019)

(DOI: 10.2169/internalmedicine.2606-19)

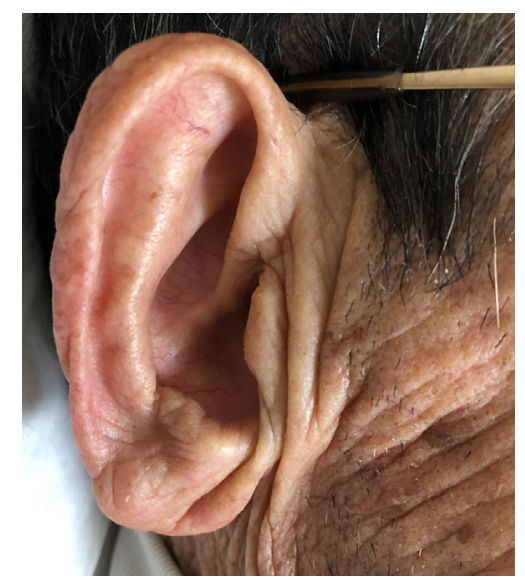

Picture.

A 73 year-old-man with a history of coronary artery disease (CAD) presented with cellulitis. On examination, Frank's sign was noted bilaterally. $\mathrm{He}$ also showed preauricular vertical creases bilaterally (Picture). Frank's sign has been reported to be a consequence of an inadequate blood supply to the earlobes lacking end arteries or the rupture and degeneration of elastin fibers in the earlobes; it is related to $\mathrm{CAD}$ with a sensitivity of $62 \%$ and specificity of
$67 \%$ (1). Frank's sign is said to be less common in Asian populations than in Westerners (2). Nevertheless, this sign can be useful, especially in young patients suspected of having CAD. Preauricular vertical creases are frequently seen with Frank's sign. As in Frank's sign, preauricular vertical creases are believed to be associated with the loss and degeneration of elastin and tears in the dermal and vascular elastic fibers. This sign can be a substitute finding to Frank's sign, especially when patients have pierced ears for earrings.

The authors state that they have no Conflict of Interest (COI).

\section{References}

1. Lucentefortea E, Romolib M, Zaglic G, Gensinid GF, Mugellia A, Vannaccia A. Ear lobe crease as a marker of coronary artery disease: a meta-analysis. Int J Cardiol 175: 171-175, 2014.

2. Wu X, Yang D, Zhao Y, Chai W, Jin M. Diagonal earlobe crease and coronary artery disease in a Chinese population. BMC Cardiovasc Disord 14: 43, 2014.

The Internal Medicine is an Open Access journal distributed under the Creative Commons Attribution-NonCommercial-NoDerivatives 4.0 International License. To view the details of this license, please visit (https://creativecommons.org/licenses/ by-nc-nd/4.0/).

Department of Diagnostic and Generalist Medicine, Dokkyo Medical University Hospital, Japan

Received: January 8, 2019; Accepted: April 16, 2019; Advance Publication by J-STAGE: June 27, 2019

Correspondence to Dr. Taro Shimizu, shimizutaro7@gmail.com

(C) 2019 The Japanese Society of Internal Medicine. Intern Med 58: 3067, 2019 